\title{
Analysis of physicochemical properties for treatment of dredged deposit soil
}

\author{
Youngshin Lee ${ }^{1}$, Sanghee Shin $^{2, *}$ \\ ${ }^{1}$ Department of Environmental Engineering, Hanseo University, Seosan, Republic of Korea \\ ${ }^{2}$ Geotechnical Engineering Research Division, Korea Institute of Construction Technology, Goyang, Republic of Korea
}

Email address:

leeys@ hanseo.ac.kr (Y. Lee), scott@kict.re.kr (S. Shin)

To cite this article:

Youngshin Lee, Sanghee Shin. Analysis of Physicochemical Properties for Treatment of Dredged Deposit Soil. American Journal of Civil Engineering. Vol. 2, No. 2, 2014, pp. 27-34. doi: 10.11648/j.ajce.20140202.13

\begin{abstract}
This study was conducted to analyze the properties of deposit soil dredged from a reservoir which was processed for efficient treatment and management. Before starting this study, the physicochemical properties and the heavy metal content of the deposit soil were investigated to collect the fundamental data. In a treatment experiment proposed to use the deposit soil, the deposit soli was separated according to the particle diameter and only the cohesive soil having a diameter of $106 \mu \mathrm{m}$ or smaller was used for plastic working after mixing it with a cross-linking agent. The dissolution experiment performed with the plastic worked deposit soil showed that the dissolution concentration was decreased as the plastic working temperature was increased. The dissolution concentration was drastically decreased especially in the $500^{\circ} \mathrm{C}$ to $1000^{\circ} \mathrm{C}$ interval of the plastic working temperature. For the future practical use, red clay was mixed with ceramic and a dissolution experiment and an experiment to calculate the saturated permeation coefficient were performed with the mixture. For the experiments, a module was prepared with the red clay to ceramic ratios of C-1 (5.3 L: red clay +ceramic=10:1), C-2 (5.3 L: red clay), and C-3 (2.65 L: ceramic, $2.65 \mathrm{~L}$ : red clay). Artificial sewage was injected to the module in which red clay and ceramic were mixed. The result showed that the pollutant dissolution concentration was higher when the dissolution time was longer. The pollutant dissolution concentration was in the order of C-1 > C-3 > C-2 with the $\mathrm{C}-1$ as the highest. The saturated permeation coefficient showed a similar tendency with that of the pollutant dissolution concentration. The result showed that the initial pollutant dissolution concentration was low in C-2 in which only pure soil was included. As time passed, the pollutant dissolution concentration of C-1 and C-3 was decreased.
\end{abstract}

Keywords: Deposit Soil, Sediment, Dissolution Concentration, Plastic, Reservoir Management

\section{Introduction}

In Republic of Korea (South Korea), reservoirs storing water for living, industry, and agriculture are continuously expanded and repaired. Inflow of nutritive salts included in domestic and industrial waste water to a reservoir causes mass propagation of various planktons or brings about eutrophication or increases the possibility of eutrophication. Artificial reservoirs are constructed by blocking river flow for stable water supply and flood control, which is one of the factors to deteriorating the water quality by forming stagnant waters $[1,2,3]$.

As the characteristics of the rainfall in Korea, the annual rainfall is concentrated on summer. Therefore, a great quantity of pollutants flowing into reservoirs from non-point pollutant sources in farmlands and mountainous regions are also discharged during the rainy season. Hence, the water quality deterioration of the inflowing water system is caused by the pollutants flowing into reservoirs from the water basin. Among the pollutant inflows, the inflow during a rainfall has a significant effect. Thus, a countermeasure against such pollutant inflow is required $[3,4,5]$.

Reservoirs located in farmlands and mountainous regions have a long water storage time because the water rainfall effluent is stored for irrigation. Along with the rainfall effluent, pollutants flowed into a reservoir is also accumulated in the reservoir. An excessive input of nutrients from the water basin causes water quality deterioration such as eutrophication of the reservoir $[6,7,8$, 9]. However, as most of the pollutants flowed into a reservoir are flowed in all at once together with the initial rainfall effluent, it is necessary to study a management technique to efficient exclude or treat the pollutants 
included in the rainfall effluent for water quality control of a reservoir [3,10,11].

Bunam Reservoir is an artificial fresh water reservoir constructed for extension of national territory by reclaimed agricultural land formation, food production increase and pastureland development by water resource protection, and modernization of agricultural industry and increase of farm income by securing of water for living and developing of backyard agricultural land. However, after the end of the reclamation project, untreated pollutants caused by the agricultural and livestock farms and by the land use in the Bunam Reservoir water basin are flowed into the reservoir. The water quality of the reservoir is gradually deteriorated as a significant quantity of pollutants is continuously flowed into the reservoir due to the insufficient sewage treatment in the upstream. In the case of the Buman Reservoir water basin, Hyundai Agricultural Association set a limit in the use of fertilizers and pesticides to the agricultural land in the past. At present, however, the agricultural land has been divided into individual farmers and thus an increased use of fertilizers and pesticides for growth enhancement is inevitable. When waters of a fresh water reservoir are stagnant and organic materials and nutrients are continuously flowed in the reservoir, the reservoir may turn to an eutrophication state as the amount of pollutants exceeds the self-purification capacity. As the problems such the environmental characteristics of the water basin, land use status, and lack of reservoir management system have been accumulated for more than 10 years, the water quality of Buman Reservoir will be more deteriorated so that even the current water quality of Grade 5 will not be maintained. In addition, the number of the tourists visiting the Zone $\mathrm{B}$ is increased due to the changes of the social conditions, leisure time use, and the increased health concerns. The habitat environment of migratory birds is also changing. Such changes in the environment of Buman Reservoir will also have a significant effect on the water quality. Therefore, it is necessary to prepare appropriate methods of improving and maintaining the fresh water quality in order to methodically and positively counteract such environmental changes.

\section{Studied Area}

The studied area belongs to Seosan-si and Taean-gun of Chungnam. Several low mountains having a sea level of 100 to $300 \mathrm{~m}$ are located in the studied area. There are piedmonts and hills but not a large river or a sedimentary plain. The coastline is a long and complicated rias coast. The shore has many extensive tidelands because the water is narrow and the tidal range is large. Many reclaimed lands have been formed because of the advantages in reclamation projects and marine development. Nam-myeon, which accounts for the greatest portion of Taean-gun in the BunamReservior basin, is a peninsula in the middle of Taean-gun, which is linked with the land at Taean-eup and Geunheung-myeon of the north and surrounded by the sea water on the other three sides. More than $65 \%$ of the total area of Nam-myeon is mountainous region. Since the height of the hills in the mountainous region is less than 74 $\mathrm{m}$, most of the hilly area is used as agricultural land. As reclaimed lands have been developed recently, a small plain has been formed. In addition, there is a well developed coastal line (Fig. 1).

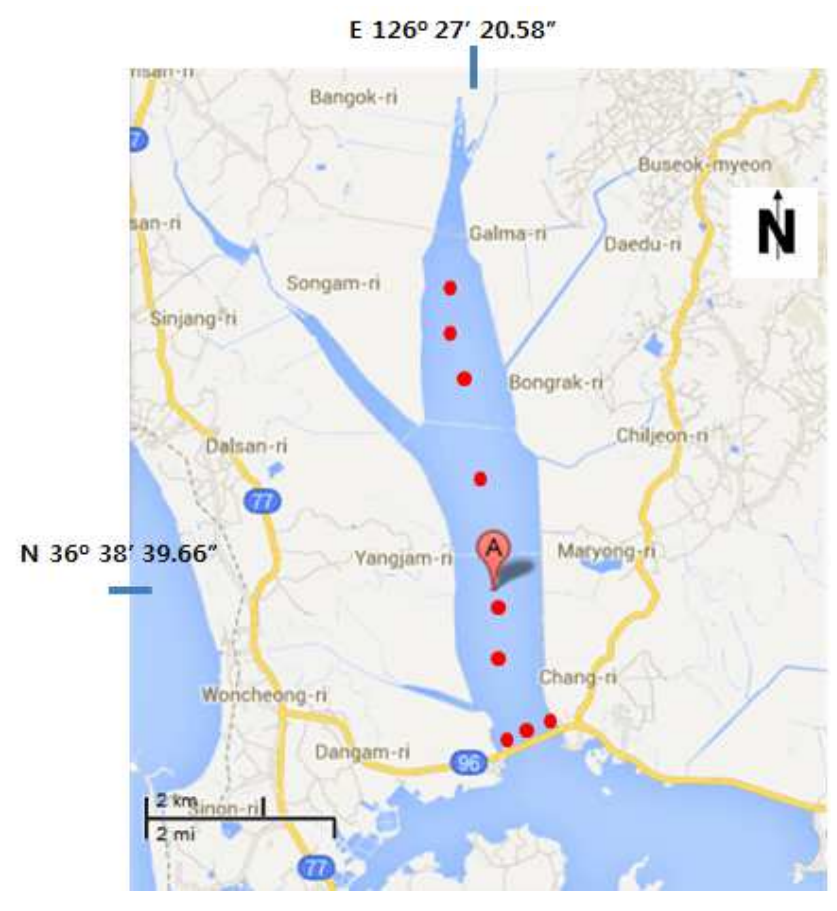

Figure 1. Location of Bunam reservoir (dot: sampling points).

\section{Use and Treatment of Sediment}

\subsection{Overview}

It is important to improve the water quality in a reservoir by dredging and treat the sediment which is a side product of dredging. Since the fresh water basin of Buman Reservoir is used for agriculture of rice production, the sediment mostly contains organic materials and nutrients, while it includes little heavy metal. When the dredged sludge is appropriately processed and reused, huge amount of coast for collection, transport, and treatment may be saved. Therefore, a plan for using the reservoir sludge should be positively prepared. In addition, when the sediment including the input pollutants is removed, production of algae due to eutrophication may be decreased, resulting in improved water quality. In addition, while the reservoir turns to anaerobic conditions with oxygen deficiency due to the anaerobic degradation of the sediment on the bottom of the reservoir, removal of the sediment may turn the reservoir to aerobic conditions so that the water quality may be improved. Since it is difficult to secure construction materials by dredging of sea sand, due to the recent sand dune protection policy of the Ministry of Environment, dredging of the reservoir sand may help to improve the water quality and secure construction materials, 
contributing to the local economic development. Moreover, the sediment composed of organic sludge and sand may be used as an organic fertilizer and an environment-friendly ground reinforcing material for the foundation work in the Buman Reservoir development region.

This study is about appropriate treatment and use of sediment which is a side product of dredging of Buman Reservoir performed as a part of the water quality improvement project. In this study, the foundation reinforcing and soil improvement properties of the sediment were investigated by analyzing the sediment properties and performing treatment tests for each sediment use.

\subsection{Methods and Contents}

\subsubsection{Studied Positions and Sampling}

To investigate the properties of the surface layer sediment of Bunam Reservoir which was the subject of this study, nine positions where the water was deep were selected, including three positions in the upstream region, one point in the midstream region, two points in the downstream region, and three points near the tide embankment. A diver was employed to collect samples of the surface sediment on the reservoir bottom, as shown in Fig. 1. The collected samples were refrigerated and transported in plastic containers.

\subsubsection{Method of Analyzing Sediment}

To analyze the properties of the sediment, the $\mathrm{pH}$, ignition loss (IG), chemical oxygen demand (COD), total nitrogen (T-N), total phosphorous (T-P), and heavy metals of the collected sediment samples were measured. Water content, IG, and T-N were measured by taking a part of an air-dried, homogenized sample. The dissolution rate of organic materials and nutritive salts was tested by the standard waste dissolution test method. According to the regulations of process test methods for each analytical item, a concentration lower than an effective detected concentration was dealt with as being undetectable.

For the use and appropriate treatment of the sediment, the treatment properties of the sediment were analyzed for each of the uses including a foundation reinforcing material and a soil improvement material. With respect to the use as a foundation reinforcing material, the sediment was properly mixed with a solidifier which is fit to the local environment and processed at an appropriate mixing ratio, and then the dissolution properties were analyzed by a dissolution experiment and a model test. In addition, to investigate the foundation reinforcing properties, a test specimen was prepared for each mixing condition and the uniaxial compressive strength of the test specimen was measured. With respect to the use as a soil improvement material, the soil composition was firstly investigated because the studied region was a reclaimed area. The useful ingredients included in the sediment were identified by separating the sediment according to the particle size. The sediment was processed into ceramic pellets for each plastic work temperature. The dissolution properties at each plastic work temperature and the discharge properties were investigated by a model test to search the appropriate plastic work temperature. The saturated permeation coefficient was evaluated to optimize the soil improvement properties of the ceramic pellets.

\section{Results}

\subsection{Analysis of Sediment Properties}

The analysis of the physicochemical properties of the sediment showed that the porosity was high, the color was dark gray due to the anaerobic change, and the smell was that of mud. As the anaerobic change progresses, the $\mathrm{pH}$ of the pore water may be lowered and the nutritive salts and heavy chemicals in the sediment may be dissolved. Therefore, the sediment may need to be appropriately treated.

\subsubsection{Physicochemical Properties of Sediment}

The average $\mathrm{pH}$ of the Bunam Reservoir sediment was 7.8 to 8.1 , indicating that it is weakly basic. Thus, the possibility that heavy metals included in the sediment are dissolved into the water body may be low. In addition, the average IG of the sediment was $13.4 \%$. With reference to the U.S. EPA sediment classification standards (non pollution $<5$, middle pollution $5-8$, hard pollution $>8$ ), the Bunam Reservoir sediment corresponds to hard pollution [12]. The pollution was more severe in the positions closer to the downstream region. The COD, which is an organic material index of sediment, was $60,214 \mathrm{mg} / \mathrm{kg}$, which corresponds to middle pollution according to the standard of the U.S. EPA (non pollution $<40,000$, middle pollution 40,00080,000 , hard pollution>80,000). When the IG and COD, the organic material indices, are minimally applied, the Bunam Reservoir sediment corresponds to middle pollution by organic materials [12]. The dissolution rate of water pollutants included in the Bunam Reservoir sediment was as low as $2.6 \%$ for COD, $41.9 \%$ for T-N, and $2.2 \%$ for T-P.

Nutritive salts such as nitrogen and phosphorous may be dissolved from sediment depending on the environmental conditions and thereby cause eutrophication and abnormal algae propagation. The sediment T-N and T-P converted into dry weight $(\mathrm{mg} / \mathrm{kg}$ ) were $3,414.6 \mathrm{mg} / \mathrm{kg}$ and $1,143.4 \mathrm{mg} / \mathrm{kg}$, respectively. With reference to the standards of Canada where there are standards for nitrogen and phosphorous (T-N: LEL 550, SEL 4,800, T-P: LEL 600, SEL 2,000), the Bunam Reservoir sediment may be adversely affected by nitrogen and phosphorous and has already been polluted by nitrogen and phosphorous [13].

Heavy metals included in sediment are important in evaluating sediment because they are directly connected with living organisms. Table 2 shows the analytical results of heavy metals included in the sediment. Due to heavy metal accumulation in the sediment caused by the high salt 
concentration and the salt dissolution, the heavy metal concentration was higher at the positions closer to the downstream region. With reference to the U.S. EPA standards, the Bunam Reservoir sediment corresponds to no heavy metal pollution.

Table 1. Physiochemical properties of sediment.

\begin{tabular}{lllllll}
\hline & Moisture(\%) & pH & I.G(\%) & COD(mg/kg) & T-N(mg/kg) & T-P(mg/kg) \\
\hline Tide embankment & 85.1 & 7.0 & 7.8 & 12.1 & 58,028 & $3,155.2$ \\
Downstream & 85.2 & 7.9 & 16.6 & 57,149 & $3,448.7$ \\
Midstream & 85.8 & 7.8 & 11.9 & 66,155 & $3,724.1$ \\
Upstream & 87.2 & 7.63 & 13.40 & 59,525 & $3,330.5$ \\
Average & 85.83 & & $60,214.25$ & $3,414.63$ \\
\hline
\end{tabular}

Table 2. Heavy metal content of sediments.

\begin{tabular}{llllll}
\hline & $\mathbf{C d}(\mathbf{m g} / \mathbf{k g})$ & $\mathbf{P b}(\mathbf{m g} / \mathbf{k g})$ & $\mathbf{C u}(\mathbf{m g} / \mathbf{k g})$ & $\mathbf{Z n}(\mathbf{m g} / \mathbf{k g})$ & $\mathbf{C r}(\mathbf{m g} / \mathbf{k g})$ \\
\hline Tide embankment & 3.3 & 6.9 & 27.5 & 132.5 & 54.8 \\
Downstream & 2.9 & 10.8 & 23.1 & 98.7 & 44.8 \\
Midstream & 3.5 & 1.7 & 23.1 & 149.6 & 63.7 \\
Upstream & 3.4 & 6.5 & 25.2 & 121.2 & 696.7 \\
Average & 3.28 & 6.48 & 24.73 & 125.50 & 60.2 \\
\hline
\end{tabular}

\subsubsection{Granularity Separation Process}

The collected samples had bad smell and color. Comparison of the sample properties showed that the sediment particle size was small, and the ratio of sand to sludge was 8:2 in the downstream region. In the upstream and midstream regions, the sediment particle size was medium, and the ratio of sand to sludge was 5:5. In the process of removing sand and moisture at a constant temperature $\left(60^{\circ} \mathrm{C}\right)$, about $50 \%$ of the sludge was removed and clay was produced, indicating that organic materials were evaporated during the process. The separation method was applied to the sediment to classify the sample into two groups with respect to the particle size of $106 \mu \mathrm{m}$. The sediment having a particle size of $106 \mu \mathrm{m}$ or larger (sand and silt) is useful as a general aggregate or a reinforcing material in construction industry. The sediment having a particle size of $106 \mu \mathrm{m}$ or smaller (clay) may be potentially used as a pellet type matrix or reinforcing material. Therefore, in this study, the sediment was separated through the granularity separation process into silt, sand, and clay. The silt and sand may be reused as construction materials, while the clay may be a matrix or a soil improvement material in the forms of mud pack or pellet.

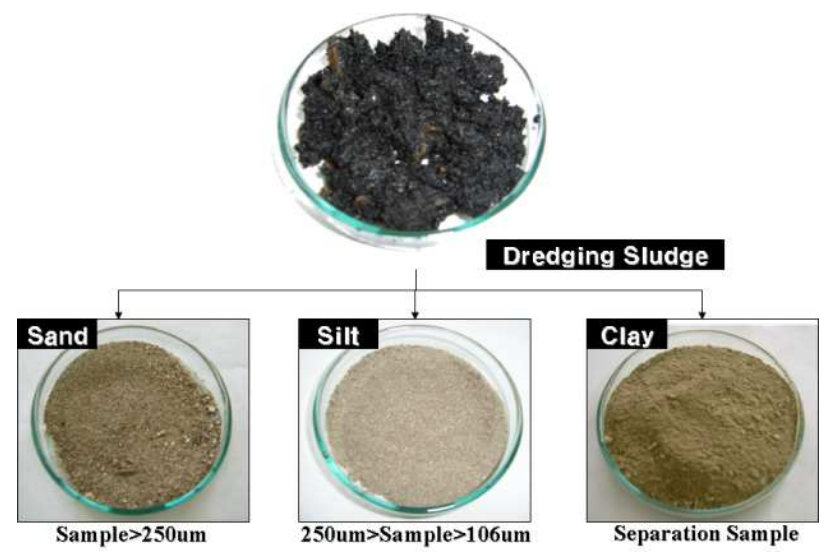

Figure 2. Separation process of sedimentation.

\subsubsection{Sediment Ceramic Plastic Properties}

Among the separated ingredients, the clay was mixed with a cross-linking agent and formulated by using a rectangular mold and applying constant pressure. The formulated clay was dried at room temperature for one day and underwent plastic work into a pellet shape. To search for the plastic work temperature appropriate for the clay having a small particle size, the plastic work was performed at the electric furnace temperature of $300^{\circ} \mathrm{C}$ and $500^{\circ} \mathrm{C}$ for one hour. It is usually anticipated that the plastic work temperature for clay is low but sintering was not performed by the sintering at the temperatures. As it was presumed that the many $\mathrm{SiO}_{2}$ particles were included in the plastic ceramic (at least more than $70 \%$ ), additional plastic work was performed at the temperature of about $1000^{\circ} \mathrm{C}$ to $1200^{\circ} \mathrm{C}$. However, a higher plastic work temperature means that more cost should be invested to the recycling (fuel cost). To solve the problem, the plastic work temperature may be decreased by adding another agent or by intensifying the initial plastic work by increasing the extrusion pressure. However, since a secondary environmental problem may arise due to the separation method and an extruder is not readily available, the method of increasing the compressive pressure may be employed at present. Then, even though the production may be decreased, the plastic work temperature may be decreased by reducing the pellet diameter and decreasing the particle size to $200 \mu \mathrm{m}$ or lower (by reducing the portion of $\mathrm{SiO}_{2}$ with which it is difficult to perform the plastic work).

\subsection{Dissolution Test}

\subsubsection{Evaluation of Dissolution at Each Plastic Work Temperature}

The dissolution of COD, T-N, T-P, and heavy metals from the proposed ceramic soil improvement material was evaluated at each plastic work temperature. To search for the optimum plastic work temperature at which the processed ceramic soil improvement material may show the least pollutant dissolution rate, the dissolution evaluation 
was performed by a method similar to the standard waste dissolution test method according to the official waste process testing method.
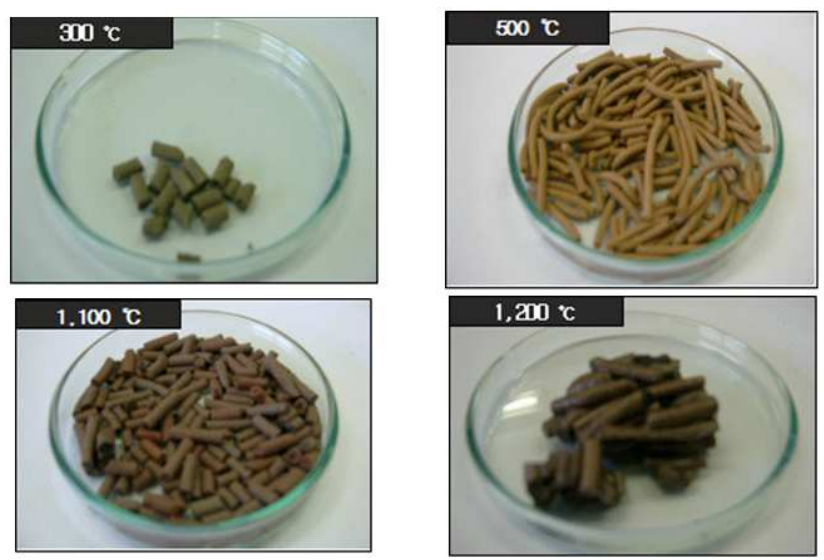

Figure 3. Ceramic plastic state of plastic temperature by sediment.

The ceramic soil improvement material prepared at each plastic work temperature was pulverized in the pretreatment process into particles having a diameter of 5 $\mathrm{mm}$ or less. Hydrochloric acid $(\mathrm{HCl})$ was added to distilled water to adjust the $\mathrm{pH}$ to 5.8 to 6.3 . The solvent and the ceramic material were mixed at a ratio of $10: 1$ and the mixture was shaken with a horizontal reciprocal shaker in the amplitude of 4 to $5 \mathrm{~cm}$ for six hours. Then, the solid and the liquid were separated by using a micro glass fiber filter and the supernatant was taken to analyze the COD, T-N, and T-P. When plastic worked ceramic is used as a soil improvement material or reclaimed, the ceramic may discharge heavy metals or hazardous substances depending on the changes of the surrounding circumstances. Thus, a heavy metal dissolution test was performed to predict the quantity and time of heavy metal dissolution from the plastic worked ceramic.

During the heavy metal dissolution test, the $\mathrm{pH}$ was kept in the range from 6.5 to 7.0 for each plastic work temperature because oxygen is combined to hydrogen to produce water as an oxidized salt of a crystallized heavy metal is ionized in a weakly acidic solution, as shown in the following chemical formula:

$$
\mathrm{MO}+\mathrm{nH}+\rightarrow \mathrm{M}++0.5 \mathrm{nH}_{2} \mathrm{O}
$$

wherein MO denotes a heavy metal oxide salt.

The pollutant and heavy metal dissolution properties at each plastic work temperature were compared. As the plastic work temperature was increased, the dissolution concentration was decreased. The dissolution concentration was drastically decreased in the temperature range from $500{ }^{\circ} \mathrm{C}$ to $1,100{ }^{\circ} \mathrm{C}$.

When the heavy metal content of the sediment before the plastic work is compared with the heavy metal dissolution after the plastic work, the dissolution is below the specific waste classification standard according to the environmental pollution process test method of the Waste Management Act of Korea. Since the quantity of heavy metal dissolution satisfies the hazardous substance content standard for the specific waste, it is presumed that the heavy metals are completely solidified. However, it was reported by Hattori that plastic work of a hazardous waste solidify the $\mathrm{Cu}, \mathrm{Zn}$, and $\mathrm{Cr}$ with the main clay ingredients such as $\mathrm{SiO}_{2}, \mathrm{CaO}$, and $\mathrm{Na}_{2} \mathrm{O}$ without any discharge of the metals to the atmosphere, making the heavy metals be included in the samples. However, it was reported that specific wastes containing materials having a low boiling point, such as $\mathrm{Cd}$ and $\mathrm{Pb}$, cause air pollution during the plastic work. Hence, it is necessary to appropriately treat materials which are volatile at a low temperature.

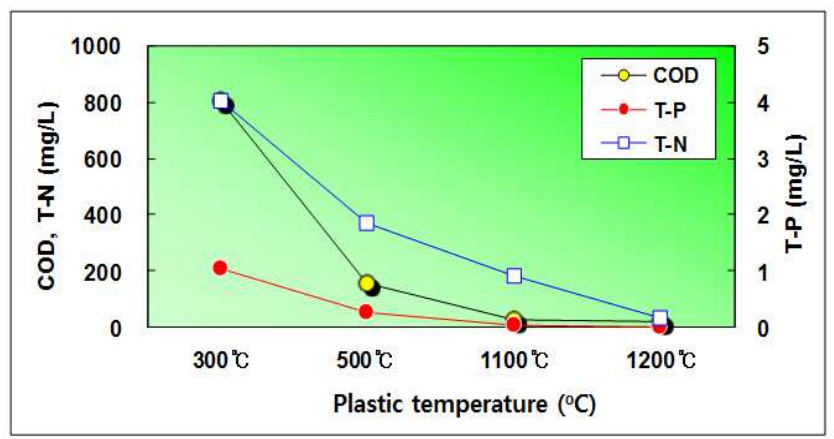

Figure 4. Comparison between plastic temperature and pollutant concentration (COD, T-N, T-P)

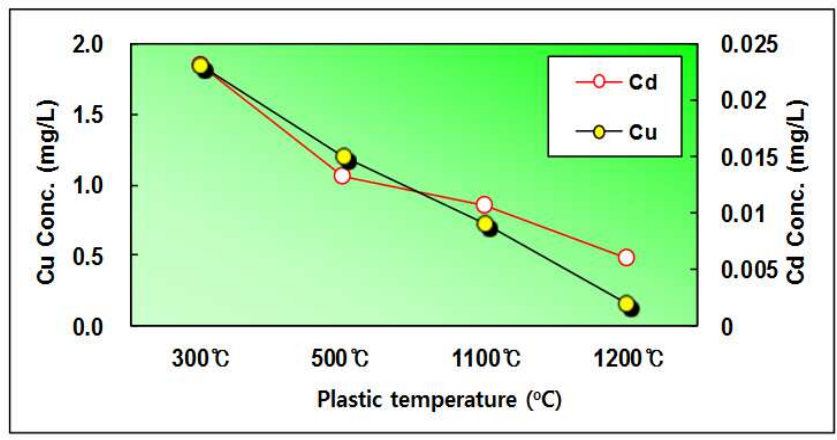

Figure 5. Comparison between plastic temperature and heavy metal concentration $(\mathrm{Cu}, \mathrm{Cd})$

\subsubsection{Discharge Evaluation by Model Experiment}

In this study, an experiment using a model was performed by preparing ceramic pellets containing clay ingredients at an appropriate plastic work time to test longterm application appropriateness for future commercialization. Through the model experiment, discharge properties such as discharge quantity, pollutant discharge rate, and permeability over time were evaluated. Table 3 shows the discharge evaluation conditions for the model experiment. In the model experiment, the basic conditions included a gravel layer and a silt layer. The varied conditions included C-1 (mixture of clay and ceramic), C-2 (clay), and C-3 (clay and ceramic) shown in Table 3. The soil used in this evaluation included gravel, sand, and clay. The experimental samples were taken from the Bunam Reservoir reclaimed land and the nearby areas. 
Table 3. Condition of the leaching assessment.

\begin{tabular}{cccc}
\hline & Condition & Condition \\
\hline Inflow velocity & $19 \mathrm{ml} / \mathrm{min}$ & Outflow time & $10 \mathrm{hrs}$ \\
Volume & $14.13 \mathrm{~L}$ & Sample & gravel layer(2.65L), \\
& silt layer (2.65L) \\
Influent water & COD 50mg/L, T-N 20mg/L, & & C-1 (5.3L: red clay +ceramic=10:1) \\
& T-P 5mg/L & Che (5.3L: red clay) \\
& (artificial sewage) & Changing condition & C-3 (2.65L: ceramic, 2.65L: red clay) \\
\hline
\end{tabular}

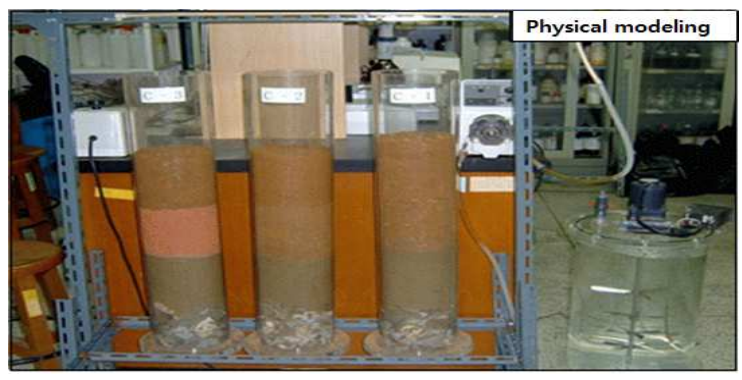

Figure 6. Apparatus used in the assessment of leaching properties.

\subsubsection{Calculation of Discharge over Time}

In the model experiment, the soil absorptivity was not good in the $\mathrm{C}-2$ reactor and thus the experiment was stopped at the elapsed time of seven hours. For the next three hours, $2.3 \mathrm{~L}$ was further discharged from the $\mathrm{C}-2$ reactor. Except the $\mathrm{C}-2$ reactor, the sewage influent after the seven hours of the elapsed time was not discharged. Fig. 7 shows the discharge patterns of the three reactors were similar with each other after three hours of the elapsed time. The discharge was in the order of $\mathrm{C}-1>\mathrm{C}-3>\mathrm{C}-2$, indicating that the discharge was faster in the soil formed by mixing clay and ceramic than in the soil prepared with clay and ceramic without mixing them together. The soil absorptivity was the lowest in the C-2 reactor in which only soil was used.

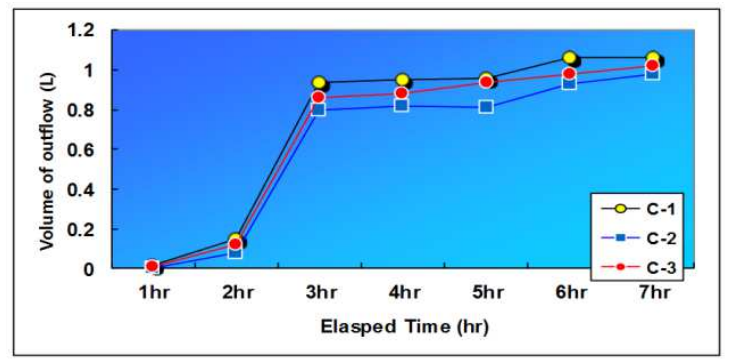

Figure 7. Changes in outflow by elapsed time.

\subsubsection{Calculation of Pollutant Discharge Rate over Time}

After three hours of elapsed time when the discharge was constant, $100 \mathrm{ml}$ of the discharged water was taken from each reactor in one hour interval to analyze the pollutants (COD, T-N, T-P, and heavy metals). To investigate the heavy metal discharge properties, an artificial sewage was prepared by dissolving $2.1 \mathrm{~g} \mathrm{CdSO}_{4}$ and $\mathrm{CuSO}_{4} \cdot 5 \mathrm{H}_{2} \mathrm{O}$ in 1 $\mathrm{L}$ of distilled water and passed through each reactor. The pollutant discharge concentration was decreased as time elapsed, and the pollutant discharge concentration was in the order of C-1 > C-3 > C-2. The result might be because the pollutants were deposited in the pores of the soil and the ceramic and thus the pollutants were not discharged. The C-2 reactor including only pure soil showed a low initial discharge concentration, but the discharge concentration of the C-1 and C-3 reactors became lower as time elapsed. The pollutant concentration was a little lower in the $\mathrm{C}-1$ reactor in which a mixture of clay and ceramic was put than in the $\mathrm{C}-3$ reactor in which clay and ceramic formed layers without mixing.

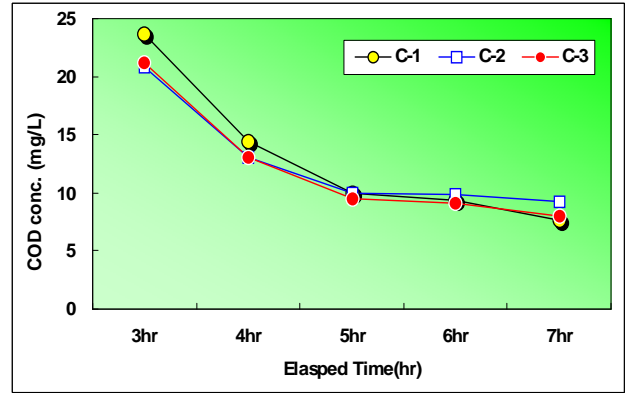

Figure 8. Changes in COD by elapsed time.

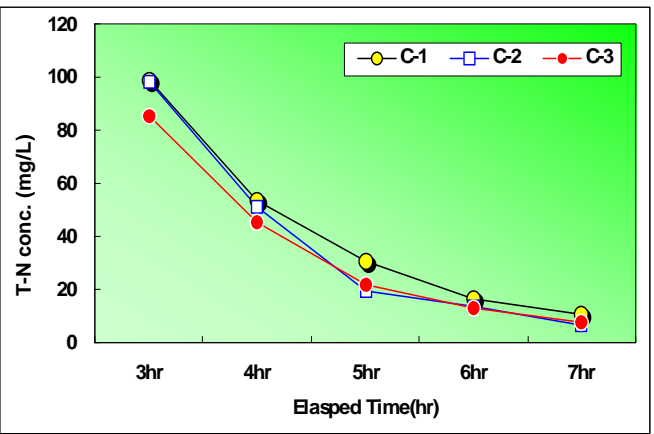

Figure 9. Changes in $T-N$ by elapsed time.

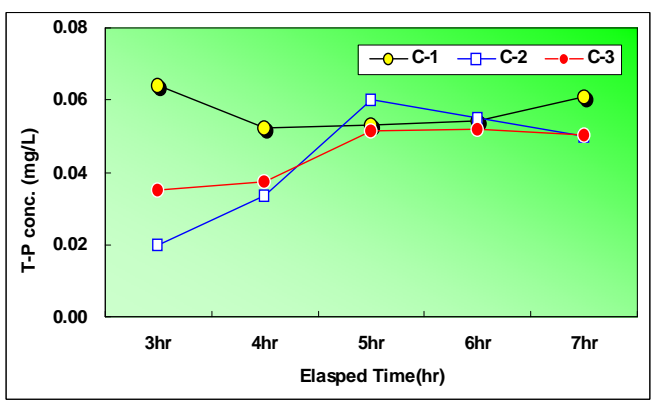

Figure 10. Changes in T-P by elapsed time. 


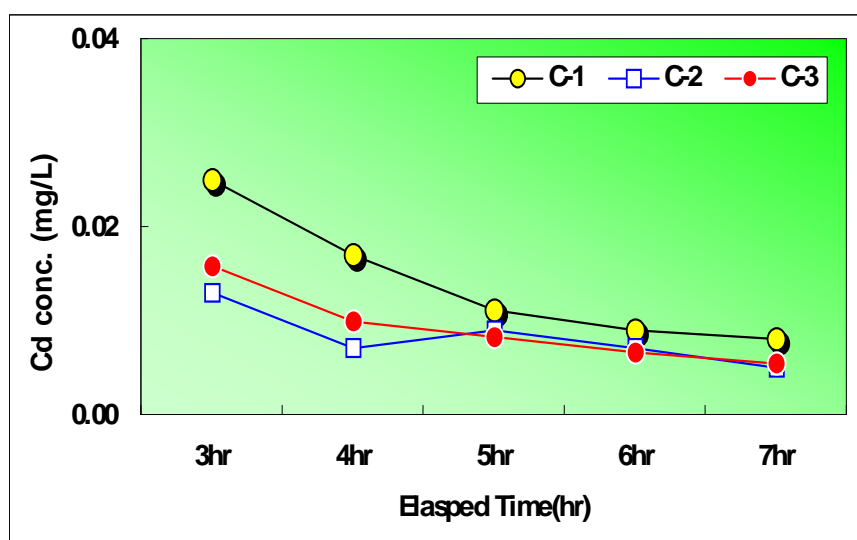

Figure 11. Changes in Cd by elapsed time.

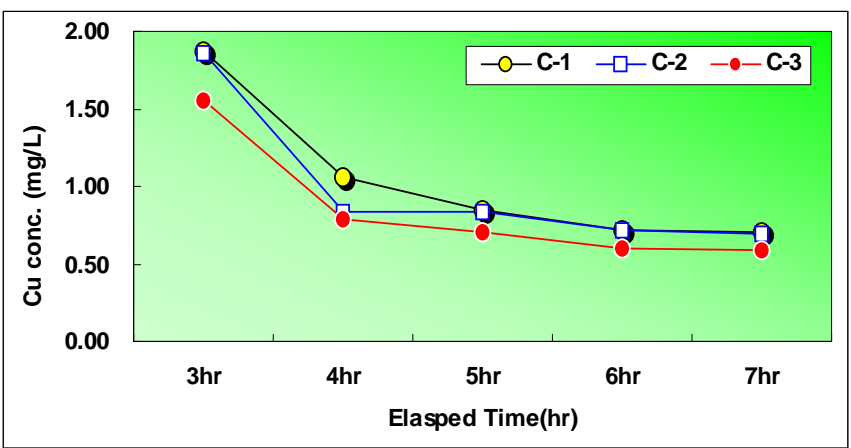

Figure 12. Changes in Cu by elapsed time.

\subsection{Soil Improvement Properties}

To evaluate actual soil improvement using optimized ceramic soil improvement materials, a model apparatus was used. The pollutant discharge rate and the discharge quantity were analyzed to review the environment effect by the secondary pollution. The saturated permeation coefficient, and lawn grass quality/leaf color were analyzed to review the role of soil improvement materials.

\subsubsection{Saturated Permeation Coefficient}

The saturated permeation coefficient of a soil on which a plant may grow is generally from $10^{-3}$ to $10^{-4} \mathrm{~cm} / \mathrm{sec}$. The soil properties obtained by the test were compared and the result showed that the saturated permeation coefficient of each reactor was a little higher than the normal plant growth range. However, the saturated permeation coefficient of the mixed soil reactor was higher than that of the pure soil reactor, which may be because compaction of the improved mixed soil makes soil consolidation slower than that of pure soil and thus decreases the permeability variation.

The saturated permeability coefficient of the saturated soil was calculated by Darcy's law:

$$
K_{s}=\frac{Q L}{A t \triangle H}
$$

where in $\mathrm{Q}$ denote flow rate, $\mathrm{L}$ sample length, A crosssectional area, $\mathrm{t}$ measurement time, and $\Delta \mathrm{H}$ differential head.

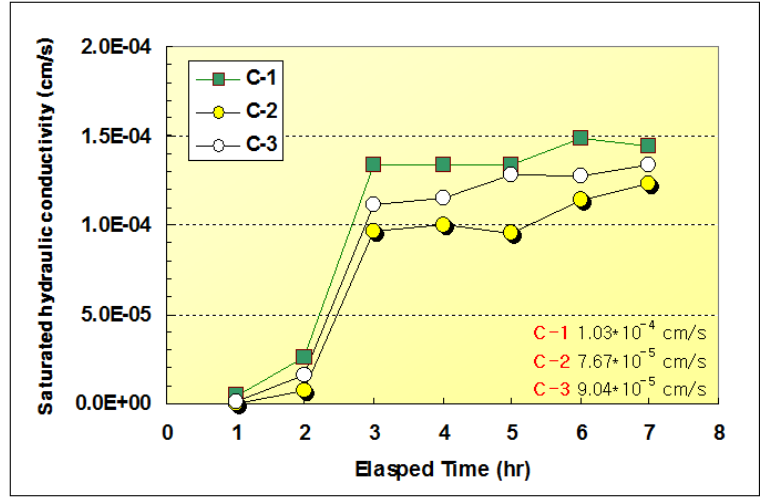

Fig 13. Saturated hydraulic conductivityby elapsed time.

\section{Conclusions}

In Bunam Reservoir, a considerable amount of sediment is accumulated on the bottom due to the deposition and sedimentation. Since the studied area was a reclaimed land lower than the sea level, foundation work of a development zone will take much cost including much construction cost. Since it is difficult to secure construction materials by dredging of sea sand, dredging of the reservoir sand and using the sediment may help to improve the water quality and secure construction materials. In this study, an experiment was performed for the case where the sediment is solidified and used as a foundation reinforcing material and for the case where the sediment undergoes ceramic plastic working and is used as a soil improvement material. When the sediment is used as a foundation reinforcing material, heavy metal dissolution should be verified since the physicochemical properties of the sediment may be changed.

The dredged sediment was classified as sand, silt, and clay. The sand and silt may be used as a construction material, while the clay may undergo ceramic plastic working and be used as a soil improvement material. The prepared samples included three types: C-1 (5.3L: red clay +ceramic=10:1), C-2 (5.3L: red clay), and C-3 (2.65L: ceramic, 2.65L: red clay). The pollutant discharge concentration was decreased as time elapsed, and the pollutant discharge concentration was in the order of C-1 > C-3 > C-2. Since the detected amount of a heavy metal included in the discharged water was little, indicating that almost no heavy metal included in the sample prepared by adding the sediment was discharged, heavy metal discharge by acid rain will be negligible. A discharge test was performed for the case where the ceramic soil improvement material is used and the test result showed that the discharge concentration was decreased as the plastic work temperature was increased. If dredging is performed in the Bunam Reservoir, the deteriorated water quality of the reservoir may be improved and the dredged sediment may be used as a construction material or a soil improvement material. The sediment containing organic sludge and sand may be used for the foundation construction work in the Bunam Reservoir development zone as organic fertilizer or 
an environment-friendly material for foundation reinforcing, which will eventually contribute to the local economic development.

\section{References}

[1] G.H. Honga, C.J. Kima, T. Yeeminb, F.P. Siringanc, J. Zhangd, H.M. Leea, K.Y. Choia, D.B. Yanga, Y. W. Ahna, and J. H. Ryua (2013). Potential release of PCBs from plastic scientific gear to fringing coral reef sediments in the Gulf of Thailand, Deep Sea Research Part II: Topical Studies in Oceanography, 96: 41-49.

[2] G.M. Friedman (1961). Distribution between dune, beach, and river sands from their textural characteristics. Journal of Sedimentary Petrology, 31(4): 514-529.

[3] Y. Lee, and S. Shin (2013). Effective reservoir management methods using nutrients leaching characteristic analysis: case study of the Hongdong reservoir. The Journal of Engineering Geology, 23(2): 95-104 (in Korean)

[4] R.T. Bannerman, D.E. Armsrtong, R F. Harris, G. C. Holdren (1975). Phosphorus uptake and release by lake Ontario sediments. US EPA, EPA-600/3-75-006, pp. 1-51.

[5] E. Calender, and D. E. Hammond (1982). Nutrient exchange across the sediment-water interface in the potomac river estuary, Estuarine. Coastal and Shelf Science, 15(4): 395413.

[6] A.M.H. Hieltjes, and L. Liklema (1980.) Fractionation of inorganic phosphates in calcareous sediments. Journal of
Environmental Quality, 9(3):405-407.

[7] J.D.H. Williams, J.K. Syers, R.F. Harris, and D.E. Armstrong (1971). Fractionation of inorganic phosphate in calcareous lake sediments. Soil Science Society of America Journal, 35(2): 250-255.

[8] J. Yang, L. Chen, L. Liu, W.S hi, and X. Meng (2014). Comprehensive risk assessment of heavy metals in lake sediment from public parks in Shanghai., Ecotoxicology and Environmental Safety, 102: 129-135.

[9] M.A.G. Darwish (2013). Geochemistry of the High Dam Lake sediments, south Egypt: implications for environmental significance.28(4): 544-559

[10] R.W. Battarbee, G.L. Simpson, E.M. Shilland, R.J. Flower, A. Kreiser, H. Yang, and G. Clarke (2014). Recovery of UK lakes from acidification: An assessment using combined palaeoecological and contemporary diatom assemblage data. Ecological Indicators, (37): 365-380.

[11] J.S. Khim, and S. Hong (2014). Assessment of trace pollutants in Korean coastal sediments using the triad approach: A review. Science of The Total Environment, 470-471: $1450-1462$

[12] United States Environmental Protection Agency (2013). Water Quality Standards Regulations and Federally Promulgated Standards. http://water.epa.gov/scitech/swguidance/standards/wqsregs.c fm.

[13] Canada Environmental Protection Agency (2012). Guidelines for Canadian Drinking Water Quality, pp. 1- 22. 